\title{
Session Introduction-Landslides as Environmental Change Proxies
}

\author{
Tomáš Pánek
}

Slope stability reacts sensitively to changes of external factors including tectonic strain, temperature and precipitation regime, permafrost degradation, sea-level oscillations and land-use patterns. Majority of these factors are recently related to global warming and increased human pressure. Despite that outcomes from recent studies supported by numerical modeling suggest indisputable link between global environmental change and changing of landslide frequency and magnitude, there is still a need for empirical data to verify these assumptions. One of the ways to bring new light to the landslide occurrence in the context of environmental changes is looking to the past and evaluation how known paleoenvironmental changes influenced landslide occurrences. Recent progress in dating techniques, monitoring and GIS technologies has brought several new challenges for the determination of the landslide temporal and spatial dynamics.

In this section category, eight papers dealing with several types of topics are presented.

Papers of Hermanns et al. and Schleier et al. concern rockslides in Norway and their temporal response to the retreat of the Scandinavian ice sheet. Results of radiometric dating and numerical modeling suggest short-time response of rock slope failures to glacier withdrawal and different dynamics of rock avalanches which originated before and after the glacier withdrawal.

S. Moreiras also discuss slope instabilities in deglaciated landscape, but in the different time scale. On the example of the Aconcagua region (Central Andes), pronounced mass movements activity within the large moraine complexes suggests permafrost degradation related to recent climate warming.

Although within different regional context, two papers from this section are looking for the link between large paleolandslides and temporal occurrence of strong earthquakes. Based on the cosmogenic radionuclide dating and historical sources, Ivy-Ochs et al. connect voluminous rock avalanche in the Trentino valley (Italy) with medieval earthquake event. Similarly, Nepop and Agatova correlate debris flow deposits with Holocene paleoearthquakes in the seismically active area of the Russian Altai.

Remaining papers present landslides as a result of environmental changes within last several decades. Two papers from the southern Italy (Pisano et al. and Gariano et al.) bring interesting insight how climate and land-use changes affect landslide occurrences and use such data for the prediction of future landslide origins. Study of Ružić et al. deals with sea-wave related increasing slope instability along the abrasion coast of the Krk Island (Croatia) with implications for the coastal hazard assessment.

Although differing in time-scale, character of landscapes and types of studied mass movements, papers in this section underline the importance of historical experience in the study of landslides. Historical analogues could be used for the calibration of numerical models and for the predictions of future landslide scenarios. In concert with increasing datasets of high-resolution paleoenvironmental proxies, dating of landslides will be more and more valuable within the process of hazard and risk assessment. 